\title{
Rheological Characterization of Warm-Modified Asphalt Mastics Containing Electric Arc Furnace Steel Slags
}

\author{
M. Pasetto, A. Baliello, G. Giacomello, and E. Pasquini \\ Department of Civil, Environmental and Architectural Engineering (ICEA), University of Padua, Via Marzolo 9, 35131 Padua, Italy \\ Correspondence should be addressed to E. Pasquini; emiliano.pasquini@unipd.it
}

Received 31 December 2015; Revised 4 February 2016; Accepted 7 February 2016

Academic Editor: Jainagesh A. Sekhar

Copyright ( 2016 M. Pasetto et al. This is an open access article distributed under the Creative Commons Attribution License, which permits unrestricted use, distribution, and reproduction in any medium, provided the original work is properly cited.

\begin{abstract}
The environmental sustainability of road materials and technologies plays a key role in pavement engineering. In this sense, the use of Warm Mix Asphalt (WMA), that is, a modified asphalt concrete that can be produced and applied at lower temperature, is considered an effective solution leading to environmental and operational benefits. The environmental sustainability of WMA can be further enhanced with the inclusion of steel slag in partial substitution of natural aggregates. Nevertheless, such innovative material applied at lower temperatures containing warm additives and steel slag should be able to guarantee at least the same performance of traditional hot mix asphalts, thus assuring acceptable mechanical properties and durability. Therefore, the purpose of this study is to investigate the rheological behaviour of bituminous mastics obtained combining a warm-modified binder and a filler (material passing to $0.063 \mathrm{~mm}$ ) coming from electric arc furnace steel slag. To evaluate the influence of both warm additive and steel slag, a plain binder and limestone filler were also used for comparison purposes. Complex modulus and permanent deformation resistance of bitumens and mastics were assessed using a dynamic shear rheometer. Experimental results showed that steel slag warm mastics assure enhanced performance demonstrating promising applicability.
\end{abstract}

\section{Introduction}

Due to continuous increase of traffic loading and taking also into account that the preservation and protection of natural and working environments have become of strategic importance, innovative road materials and products should be considered to enhance environmental sustainability of pavements without affecting (and, actually, improving) their mechanical performance and durability.

In this sense, the use of Warm Mix Asphalt (WMA) has gained increasing interest since it is a modified asphalt concrete, obtained by using different types of additives, which can be produced, applied, and compacted at lower temperatures $\left(100-140^{\circ} \mathrm{C}\right)$ than hot mix asphalt (HMA). WMA should be able to guarantee environmental benefits (reduced energy consumption, gas and fume emissions) as well as economic/operational advantages such as lower production costs, longer hauling distances, and extended construction periods $[1,2]$. The mechanical properties (benefits and drawbacks) of WMA mixes can vary in a large range mainly depending on the amount of additive and the type of WMA technology used. Wide scientific literature exists addressing the assessment of mechanical properties and durability of warm-modified binders and mixtures [2-11].

Including steel slag in substitution of natural aggregates within WMA can further enhance the environmental sustainability of such a mixture, since natural resources (natural aggregates) can be saved and industrial waste (steel slag) can be reused. The interest in ferrous slag as valuable resource for construction applications (including road pavements) is increasing steadily, taking also into account that hundreds of millions of tons of this material is produced worldwide annually affecting the environment [12]. In particular, steel slag is a by-product of the steelmaking and steel refining processes usually categorized based on the type of furnace used. In this sense, the more common steel slags are basic oxygen furnace (BOF) and electric arc furnace (EAF) steel slag $[12,13]$. Several studies documenting benefits and drawbacks related to the use of steel slags in road pavements under mechanical, functional, and environmental point of 
TABLE 1: Basic properties of the studied binders.

\begin{tabular}{|c|c|c|c|c|}
\hline \multirow{2}{*}{ Properties } & \multirow{2}{*}{ Standard } & \multirow{2}{*}{ Unit } & \multicolumn{2}{|c|}{ Value } \\
\hline & & & Binder P & Binder W \\
\hline Penetration at $25^{\circ} \mathrm{C}$ & EN 1426 & $0.1 \mathrm{~mm}$ & 38 & 39 \\
\hline Softening point & EN 1427 & ${ }^{\circ} \mathrm{C}$ & 65 & 62 \\
\hline Viscosity at $135^{\circ} \mathrm{C}$ & EN 13302 & $\mathrm{~Pa} \cdot \mathrm{s}$ & 0.27 & 0.25 \\
\hline Mass loss after short term aging (RTFOT) & EN 12607-1 & $\%$ & 0.01 & 0.03 \\
\hline Penetration at $25^{\circ} \mathrm{C}$ after RTFOT & EN 1426 & $0.1 \mathrm{~mm}$ & 23 & 24 \\
\hline Softening point after RTFOT & EN 1427 & ${ }^{\circ} \mathrm{C}$ & 72 & 71 \\
\hline
\end{tabular}

TABLE 2: Basic properties of the studied fillers.

\begin{tabular}{lcccc}
\hline Properties & Standard & Unit & \multicolumn{2}{c}{ Value } \\
& & $\mathrm{Mg} / \mathrm{m}^{3}$ & Limestone & 2.74 \\
Particle density & EN 1097-7 & - & $\mathrm{NP}$ & 3.86 \\
Plasticity Index & CEN ISO/TS 17892-12 & $\%$ & 32.7 & $\mathrm{NP}$ \\
Rigden voids & $\mathrm{EN} \mathrm{1097-4}$ & ${ }^{\circ} \mathrm{C}$ & 60.4 \\
Delta R\&B temperature & EN 13179-1 & & 5.8 & 22.1 \\
\hline
\end{tabular}

view can be found in the literature [14-23]. However, only little research exists about the possibility of using steel slag in WMA [24].

In this sense, the basic challenge of such innovative material (WMA including steel slag) is the production of a pavement mixture characterized by at least the same performance of traditional HMA, thus able to assure acceptable in-service mechanical performance and durability. Therefore, this study is addressed to the assessment of rheological properties of mastics, that is, the blend of bitumen and filler, since it is well known that the major distresses in bituminous pavements are principally related to mastic performance. In fact, the filler mainly stiffens the bitumen decisively influencing, as a function of its nature and composition, the mechanical properties of asphalt mixtures in terms of cracking and rutting resistance [25-32].

Given this background, this research study was carried with the objective of evaluating the influence of both warm chemical additive and EAF steel slag filler on the rheological behaviour of bituminous binders and mastics at midrange and high service temperature. To accomplish this objective, two bitumens and four mastics of different nature and composition were studied at unaged and long-term aged conditions through a dynamic shear rheometer (DSR). Such a study is a part of a wider research project aimed at assessing the feasibility of using EAF steel slag in WMA taking into account workability, mechanical properties, and durability of binders, mastics, and mixtures [33].

\section{Materials and Methods}

2.1. Materials. Plain bitumen was selected as the base reference binder for this study. A commercial WMA additive was added to the plain bitumen to obtain the warm-modified binder. Then, four mastics were produced by adding to the above-mentioned plain and warm bitumens two types of fillers dosed at a constant filler/bitumen volume ratio.

The plain bitumen was 35/50 penetration grade bitumen regularly used in central and southern Europe for pavement construction whereas the WMA additive was a chemical additive consisting in a water-free liquid product containing surface active agents. An additive dosage of $0.5 \%$ by weight of binder was selected to obtain the warm binder as recommended by the producer and according to the study on mixtures [33]. The warm binder was produced in the laboratory using a portable mixer operating at high stirring rates blending the prefixed amount of liquid additive and the hot plain binder $\left(150^{\circ} \mathrm{C}\right)$. Table 1 shows the basic properties of both plain (P) and warm-modified (W) bitumens. It is worth noting that, according to other studies [8], no significant differences can be detected between the two binders from these traditional tests.

$\mathrm{P}$ and $\mathrm{W}$ binders were used to prepare mastics by using two types of filler. The fillers selected for these studies (Figure 1) consisted of particles passing the $0.063 \mathrm{~mm}$ sieve and coming from natural (limestone) and manufactured (electric arc furnace steel slag) sources, respectively. The main properties of such fillers are reported in Table 2. Moreover, as reported in a previous study [18], the chemical composition of both materials is given in Table 3. It is worth noting that the two materials are characterized by very different physical (Table 2) and chemical (Table 3 ) properties that will allegedly affect rheological behaviour of mastics.

Mastics were prepared in the laboratory by heating fillers and bitumens (both plain and warm-modified) at $150^{\circ} \mathrm{C}$ for 1 hour. Then, fillers were slowly added with accurate blending in order to achieve homogeneous mixes without filler segregation. Mastics were produced at a constant filler-bitumen (by volume) ratio. Since the apparent specific gravity of steel slag is significantly higher than that of mineral aggregate, the 


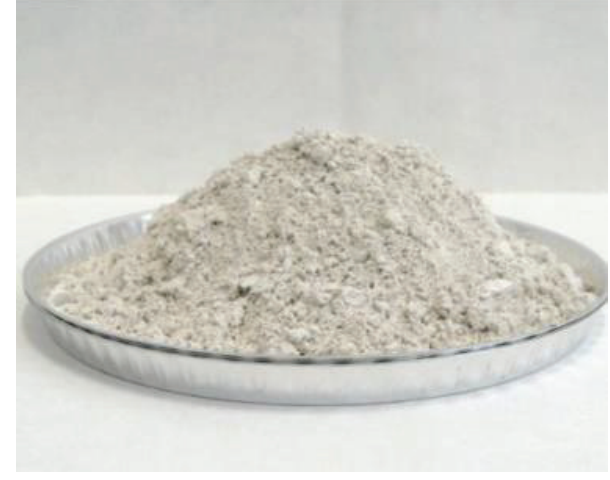

(a)

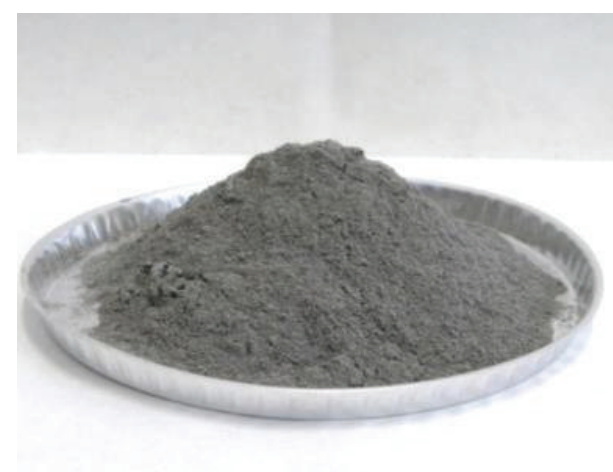

(b)

FIGURE 1: Limestone (a) and electric arc furnace (EAF) steel slag (b) filler.

TABLE 3: Chemical composition of the studied fillers.

\begin{tabular}{lcc}
\hline $\begin{array}{l}\text { Oxide content } \\
{[\%]}\end{array}$ & Limestone & Filler type \\
\hline $\mathrm{MgO}$ & 2.50 & Steel slag \\
$\mathrm{Al}_{2} \mathrm{O}_{3}$ & 1.00 & 3.65 \\
$\mathrm{SiO}_{2}$ & 3.34 & 9.30 \\
$\mathrm{CaO}$ & 52.71 & 13.02 \\
$\mathrm{TiO}_{2}$ & - & 29.60 \\
$\mathrm{Cr}_{2} \mathrm{O}_{3}$ & - & 0.35 \\
$\mathrm{MnO}$ & - & 4.03 \\
$\mathrm{FeO}$ & 0.39 & 5.09 \\
\hline
\end{tabular}

dosages of bitumens and filler were selected to obtain $27 \%$ filler and $73 \%$ binder by volume for both limestone and steel slag mastics. In accordance with Superpave specifications [34], such composition corresponds to a filler-bitumen ratio by mass equal to 1.0 in the case of limestone mastics and to 1.4 by mass in the case of steel slag mastics. Mastics were prepared with both unaged and long-term aged binders in order to reproduce real field conditions. Long-term aging was simulated in the laboratory through the pressure aging vessel (PAV) procedure, according to EN 14769 specifications. Short-term aging was not taken into account since the traditional procedure could not be representative of shortterm aging really experienced by WMAs due to different mixing, transportation, and application temperatures of such mixes. Special care was then paid to the thermal history and the storage conditions of the test sample. All specimens were subjected to a 1-day storage period at $25^{\circ} \mathrm{C}$ before testing to avoid any possible residual stress due to pouring and mixing operations.

Thus, 12 materials (bitumens and mastics) were prepared to be tested in this study as described in Table 4 .

2.2. Testing Program and Methods. A dynamic shear rheometer (DSR) was used to accomplish the main objective of the study, that is, to characterize midrange and high
TABLE 4: Tested materials.

\begin{tabular}{lccc}
\hline Material code & Filler type & Bitumen Type & Bitumen aging \\
\hline P & - & Plain (hot) bitumen & Unaged \\
P_A & - & Plain (hot) bitumen & PAV-aged \\
PL & Limestone & Plain (hot) bitumen & Unaged \\
PL_A & Limestone & Plain (hot) bitumen & PAV-aged \\
PS & EAF steel slag & Plain (hot) bitumen & Unaged \\
PS_A & EAF steel slag & Plain (hot) bitumen & PAV-aged \\
\hline W & - & Warm bitumen & Unaged \\
W_A & - & Warm bitumen & PAV-aged \\
WL & Limestone & Warm bitumen & Unaged \\
WL_A & Limestone & Warm bitumen & PAV-aged \\
WS & EAF steel slag & Warm bitumen & Unaged \\
WS_A & EAF steel slag & Warm bitumen & PAV-aged \\
\hline
\end{tabular}

service temperatures behaviour of warm-modified binder and mastics containing EAF steel slag. In particular, the experimental plan schematized in Figure 2 was developed to achieve the research goal. Unaged materials (binder and mastics) were tested through oscillatory Multiple Stress Creep Recovery (MSCR) tests in order to evaluate their rutting potential (high service temperature properties). Moreover, the complex shear modulus at midrange service temperatures of long-term aged materials was analysed through the construction of master curves applying the time-temperature superposition principle.

Linear viscoelastic behaviour (norm of the complex shear modulus $\left|G^{*}\right|$ and phase angle $\delta$ ) of the studied materials at midrange service temperatures was defined performing strain-controlled frequency sweeps from 0.1 to $100 \mathrm{rad} / \mathrm{s}$ at eight temperatures, ranging from 16 to $58^{\circ} \mathrm{C}$. A strain level of $0.05 \%$ was applied on the basis of the results of preliminary amplitude strain sweeps carried out at $10 \mathrm{rad} / \mathrm{s}$ checking the extension of the linear viscoelastic domain. $8 \mathrm{~mm}$ parallel plate geometry with $2 \mathrm{~mm}$ gap or $20 \mathrm{~mm}$ parallel plate geometry with $1 \mathrm{~mm}$ gap was used depending on the testing temperature (different expected stiffness). 30 minutes' 


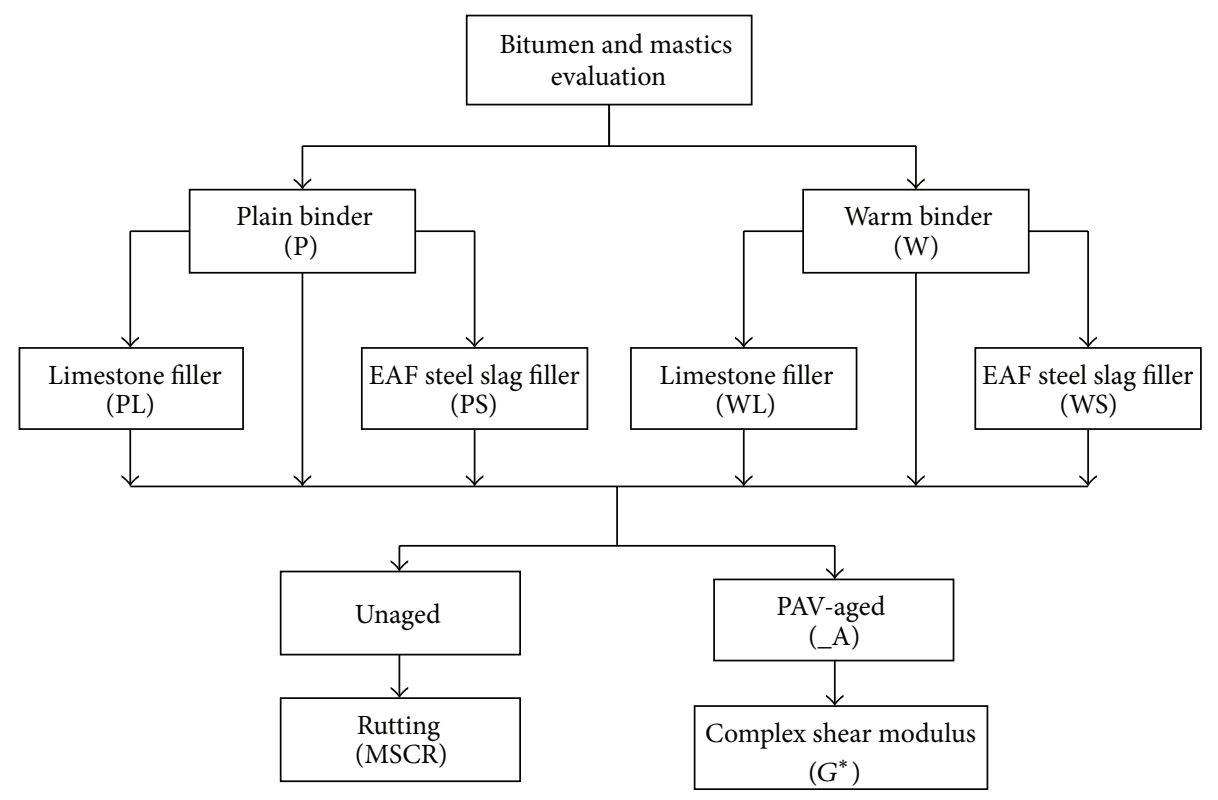

Figure 2: Experimental plan.

thermal conditioning at the test temperature was carried out before testing. Two replicates were performed for each test temperature and frequency. The rheological behaviour of the binders and mastics at midrange service temperatures was described by applying the time-temperature superposition principle. This was accomplished obtaining master curves in a wide range of reduced frequencies by shifting isothermal curves of complex modulus $G^{*}$ using temperature-dependent shift factors. The Williams-Landel-Ferry (WLF) formulation [35] is used in the model to express the temperature-shift factor. The master curve model showed below [36] was used to fit DSR test results:

$$
G^{*}\left(f^{\prime}\right)=G_{e} \frac{G_{g}-G_{e}}{\left[1+\left(f_{c} / f^{\prime}\right)^{k}\right]^{m_{e} / k}}
$$

where $G_{e}$ is the equilibrium complex modulus (equal to 0 for binders), $G_{g}$ is the glass complex modulus (usually $10^{9} \mathrm{~Pa}$ for binders), $f_{c}$ is a frequency location parameter, and $f^{\prime}$ is the reduced frequency obtained by the product of the test frequency and the temperature shift factors $a(T)$, whereas $k$ and $m_{e}$ are dimensionless shape parameters. In particular, $G_{g}$ represents the horizontal asymptote at very high frequencies whereas $G_{e}$ is the horizontal asymptote at very low frequencies. $G_{e}$ represents the minimum modulus that a mixture can offer when the contribution of the binder is assumed to be negligible whereas $G_{g}$ is the maximum asymptotic modulus representing the condition corresponding to the higher contribution of the binder to the mixture modulus. The model is also characterized by a third asymptote having a slope of $m_{e}$. $G_{g}$ and $m_{e}$ asymptotes intercept at frequency $f_{c}$. At this frequency it is possible to calculate parameter $R$ that represents, on a logarithmic scale, the distance between $G^{*}$ and $G_{g} . R$ is thus defined as

$$
R=\log \frac{2^{m_{e} / k}}{1+\left(2^{m_{e} / k}-1\right)\left(G_{e} / G_{g}\right)}
$$

and it is an indicator of the width of the relaxation spectrum. A more gradual transition from the elastic to the viscous behaviour leads to higher $R$ value, generally indicating lower $G^{*}$ values and higher phase angles within the intermediate range of frequency. On the other hand, parameter $f_{c}$ represents the frequency at which the elastic component $\left(G^{\prime}\right)$ and the viscous component $\left(G^{\prime \prime}\right)$ are approximately equal. A higher value of $f_{c}$ means a higher phase angle and thus a greater overall viscous component.

The corresponding model for the phase angle introduced by [36] is

$$
\delta=90 I-\left(90 I-\delta_{m}\right)\left\{1+\left[\frac{\log \left(f_{d} / f^{\prime}\right)}{R_{d}}\right]^{2}\right\}^{-m_{d} / 2}
$$

where $I$ is a constant value equal to 0 or 1 if $f^{\prime}>f_{d}$ or $f^{\prime} \leq f_{d}$, respectively (0 for mixtures), $\delta_{m}$ is a shape constant (value of $\delta$ at $\left.f_{d}\right), f_{d}$ is a frequency location parameter at which $\delta_{m}$ occurs, and $f^{\prime}$ is the above-mentioned reduced frequency whereas $R_{d}$ and $m_{d}$ are dimensionless shape parameters.

Multiple stress creep recovery (MSCR) tests were carried out according to ASTM D7405 to evaluate the rutting behaviour of studied materials. Elastic and plastic behaviour as well as the stress dependence of bituminous materials were assessed through these tests. The MSCR tests were performed using $20 \mathrm{~mm}$ parallel plate geometry with $1 \mathrm{~mm}$ gap. Tests consisted of 10 creep-recovery cycles with a creep loading time of $1 \mathrm{~s}$ and recovery time (with no loading) of $9 \mathrm{~s}$. The MSCR tests were conducted on unaged materials. 


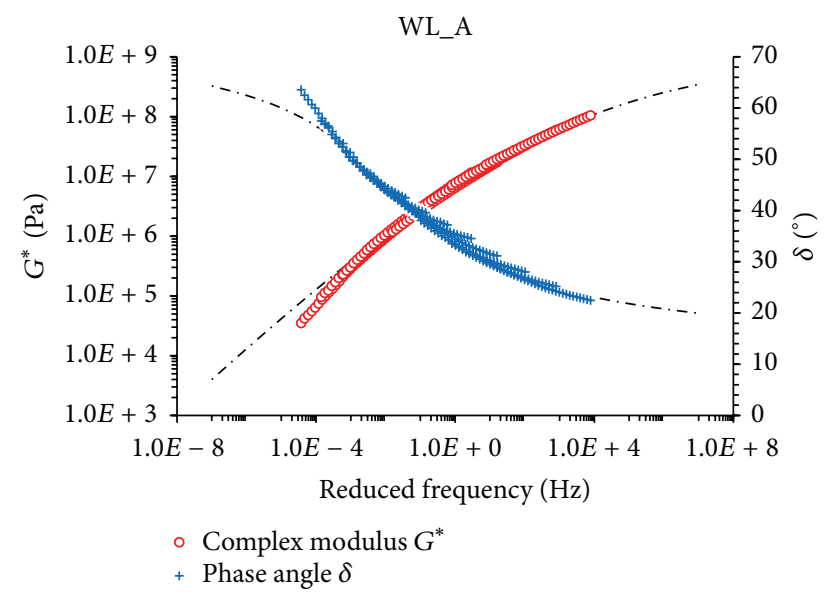

Figure 3: Master curves at $34^{\circ} \mathrm{C}$ and measured shifted data for $G^{*}$ and $\delta$ (sample WL_A).

Temperature and stress dependency of bitumens and mastics were evaluated by performing MSCR tests at 58, 64, 70, and $76^{\circ} \mathrm{C}$ applying 0.1 and $3.2 \mathrm{kPa}$. An additional higher stress level $(10 \mathrm{kPa})$ was considered for the mastics according to previous studies $[28,37]$. Specimens were conditioned at the test temperature for 20 minutes before testing. Two replicates were carried out for each material and testing condition. Average values were used to assess the resistance to permanent viscous strains typical of the rutting processes. In particular, the experimental results were analysed in terms of (i) the nonrecoverable creep compliance $\left(J_{\mathrm{nr}}\right)$, that is, the mean value of the ratio between residual (plastic) strain at the end of each cycle (postrecovery phase) and the corresponding applied creep stress and (ii) the ratio between nonrecoverable $J_{\mathrm{nr}}$ and total compliance $J_{\text {tot }}$, that is, the compliance at load removal (at the end of the creep phase).

\section{Results}

3.1. Midrange Service Temperature Behaviour. Frequency sweeps tests carried out through the DSR in a wide range of temperatures and frequencies were used to assess the viscoelastic behaviour of tested binders and mastics at midrange service temperatures. Results of the material WL_A are reported, as an example, in Figure 3 in terms of complex modulus and phase angle master curves at the reference temperature of $34^{\circ} \mathrm{C}$. Such experimental data are also reported in the Cole-Cole plane $\left(G^{\prime}, G^{\prime \prime}\right)$ and Black diagram or van GurpPalmen plot $\left(G^{*}, \delta\right)$ as depicted in Figure 4. Results seem to show a unique curve identifying the material response. Therefore, a thermorheologically simple behaviour can be assumed considering the time-temperature superposition principle generally valid for $G^{*}$ in the investigated range of reduced frequencies.

The model parameters described in (1) and (2) are showed in Table 5. First of all, it is worth noting that $G_{g}$ and $G_{e}$ values are not reported in the table since, also in the case of mastics, they tend to $10^{9}$ and $0 \mathrm{~Pa}$, respectively. As known, such values are typical of bitumens confirming that the rheological
TABLE 5: Estimated parameters for $G^{*}$ master curves.

\begin{tabular}{lcccc}
\hline Material & $\begin{array}{c}f_{c} \\
{[\mathrm{~Hz}]}\end{array}$ & $\begin{array}{c}m_{e} \\
{[-]}\end{array}$ & $\begin{array}{c}k \\
{[-]}\end{array}$ & $\begin{array}{c}R \\
{[-]}\end{array}$ \\
\hline P_A & 398.5 & 0.56 & 0.108 & 1.58 \\
PL_A & 333.7 & 0.56 & 0.136 & 1.25 \\
PS_A & 320.5 & 0.50 & 0.163 & 0.93 \\
\hline W_A & 441.2 & 0.56 & 0.097 & 1.72 \\
WL_A & 390.8 & 0.55 & 0.126 & 1.31 \\
WS_A & 359.6 & 0.44 & 0.157 & 0.85 \\
\hline
\end{tabular}

properties of all investigated materials mainly depend on the bituminous component. This seems in accordance to the model proposed by [26] which shows that the selected concentration of fillers falls within the diluted region where the available bitumen is not completely influenced by the filler.

Experimental results are also depicted in Figure 5 where real shifted data are not reported for the sake of readability.

It can be observed that the addition of the warm chemical additive did not lead to a simple horizontal translation of the $G^{*}$ master curve. In particular, in the case of bitumen and mineral limestone mastic, the warm materials seem characterized by a quasi-negligible stiffness decrease at high reduced frequencies (with virtually no difference as reduced frequency decreases) with respect to the corresponding hot materials. On the other hand, a different behaviour is observed when the warm additive is coupled with EAF steel slag filler, denoting a different physical-chemical interaction between the components and thus highlighting the importance of filler mineralogy and physical properties in the additive-filler interaction. In any case, according to previous studies [8], the most significant effect due to the warm modification is the reduced phase angle, especially at low reduced frequencies (i.e., at high temperatures) suggesting a more elastic response of such materials in the linear viscoelastic domain. In this sense, the negative effect of higher $G^{*}$ at midrange service temperatures can be mitigated by the reduction of $\delta$, thus making the materials less brittle.

Moreover, as far as the effect of the filler is concerned, Figure 6 clearly shows the predictable stiffness increase due to the addition of fillers for both plain and warm binders. On the other hand, negligible variations of the phase angle seem to occur, except for the case of warm binder with EAF steel slag filler, which denoted a less viscous response at low reduced frequencies. Such different viscoelastic behaviour of the two studied mastics seem confirmed by the lower $R$ and $f_{c}$ values of steel slag mastic, indicating a variation of the relaxation spectrum and viscous response in the linear viscoelastic domain towards a more elastic material.

It is worth reminding that bitumens and mastics are characterized by more elastic response at high frequencies (low temperatures) and more viscous behaviour at low frequencies (high temperatures). In this sense, useful information can be obtained by plotting $G^{\prime}$ and $G^{\prime \prime}$ as a function of reduced frequencies [38]. As an example, Figure 7 reports data of WL_A showing that the storage modulus is higher than the loss modulus at high frequencies (more elastic behaviour) 


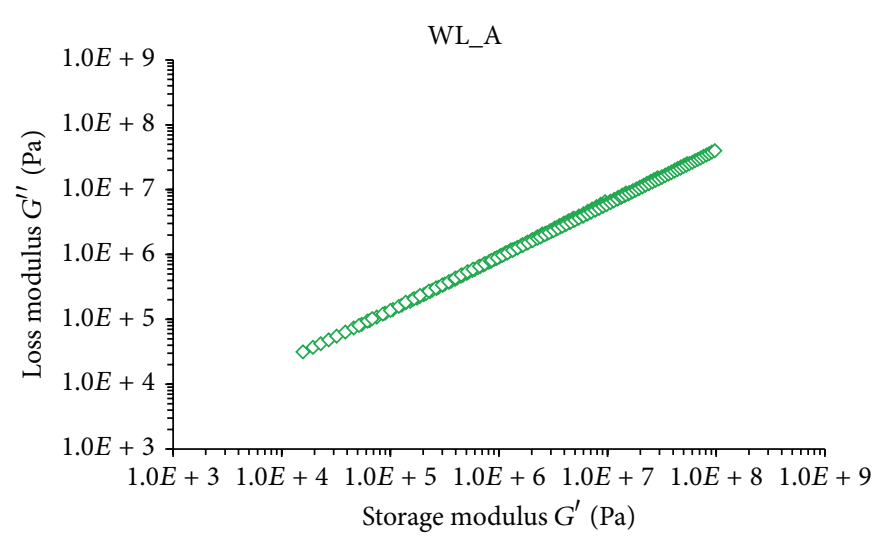

(a)

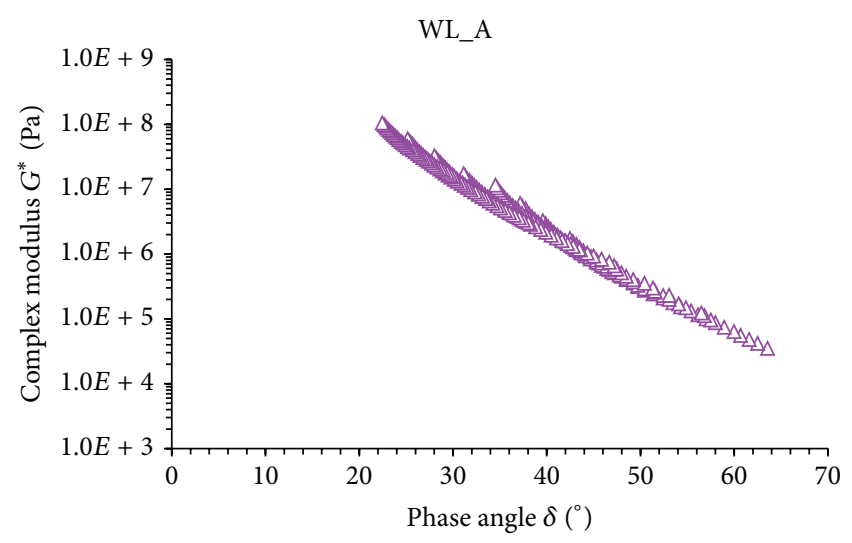

(b)

Figure 4: Cole-Cole plot (a) and Black diagram (b) for the complex modulus $G^{*}$ (sample WL_A).

whereas the loss modulus tends to become higher at very low reduced frequencies.

However, regardless of $G^{\prime} / G^{\prime \prime}$ ratio of each material, Figure 8 shows that WS_A is characterized by noticeably higher storage modulus than the other warm samples, particularly at low reduced frequencies, confirming previous findings (Figure 6(d)).

3.2. High Service Temperature Behaviour. Repeated creeprecovery tests were carried out through the DSR to evaluate the rutting potential of studied binders and mastics. Experimental results in terms of nonrecoverable creep compliance $J_{\mathrm{nr}}$ as a function of test temperature are showed in Figure 9, for both 0.1 and $3.2 \mathrm{kPa}$ stress levels. Obviously, $J_{\mathrm{nr}}$ increased with test temperature for all materials confirming that higher permanent strains will develop at higher temperatures due to higher viscous behaviour. Similar trends were observed for all binders and mastics as a function of temperature and/or applied stress level, highlighting similar temperature susceptibility and no stress dependence within the selected testing conditions.

The influence of the warm additive on the nonrecoverable creep compliance seems negligible for all binders and mastics (except for the positive effect in the case of mastics containing steel slag at lower test temperature) suggesting that, according to previous research findings $[7,8,33]$, such additive should not compromise rutting resistance with respect to the corresponding traditional hot material. On the other hand, the stiffening effect due to the addition of fillers, leading to the reduction of the rutting potential of mixtures, is clearly demonstrated by the sensibly reduced $J_{\mathrm{nr}}$ at all test temperatures with respect to the corresponding bitumens. This fact is particularly true in the case of mastics prepared with EAF steel slag filler revealing distinct aptitude of such material against permanent deformations and confirming that a physical-chemical interaction occurs between fillers and bitumens, also in accordance with the frequency sweep test results. Due to similar trends of all materials as a function of temperature and applied stress level, it is possible to assert that the stiffening effect of fillers is not temperature and stress dependent.
For a better characterization of permanent deformation resistance of materials, the ratio between nonrecoverable $J_{\text {nr }}$ and total compliance $J_{\text {tot }}$, that is, the compliance at load removal (at the end of the creep phase), should be considered taking also into account the creep phase of the test [39]. It is worth noting that this ratio can vary from 0 (elastic material completely recovering the accumulated strain) to 1 (viscous material not recovering any accumulated strain). Experimental data reported in Figure 10 in terms of percentage demonstrate that the elastic response of materials is both temperature and stress dependent, decreasing as temperature and stress level increase. Results also show that the plain bitumen $\mathrm{P}$ was characterized by $J_{\mathrm{nr}} / J_{\text {tot }}$ value close to $100 \%$ at any testing condition suggesting a minor rutting resistance since it does not seem able to recover deformations.

A slight decrease of $J_{\mathrm{nr}} / J_{\text {tot }}$ ratio can be noted at $0.1 \mathrm{kPa}$ due to the addition of the limestone filler highlighting a very low (negligible) performance increase that disappeared at higher stress levels. On the contrary, in accordance with nonrecoverable creep compliance and viscoelastic response, the addition of EAF steel slag led to a noticeably enhancement of antirutting elastic properties of bitumens, especially at lower test temperatures and stress levels as well as when mixed with the warm binder $\mathrm{W}$, stressing the significance of additive-filler physical-chemical interaction [28].

In this sense, it is worth noting that, according to previous studies [8] and confirming frequency sweep test results, warm materials (bitumens and mastics) prepared with the chemical additive generally exhibited higher rutting resistance with respect to the corresponding hot materials demonstrating the ability to enhance the rheological behaviour (elastic response) of mixtures against permanent deformations. In particular, it is significant that the only tested material showing some resilient properties also at $10.0 \mathrm{kPa}$ stress level was the warm mastic prepared with EAF steel slag filler.

\section{Conclusions}

This paper presents a part of a wider research project aimed at assessing the feasibility of using electric arc furnace steel slag as aggregate within dense graded warm mix asphalts 


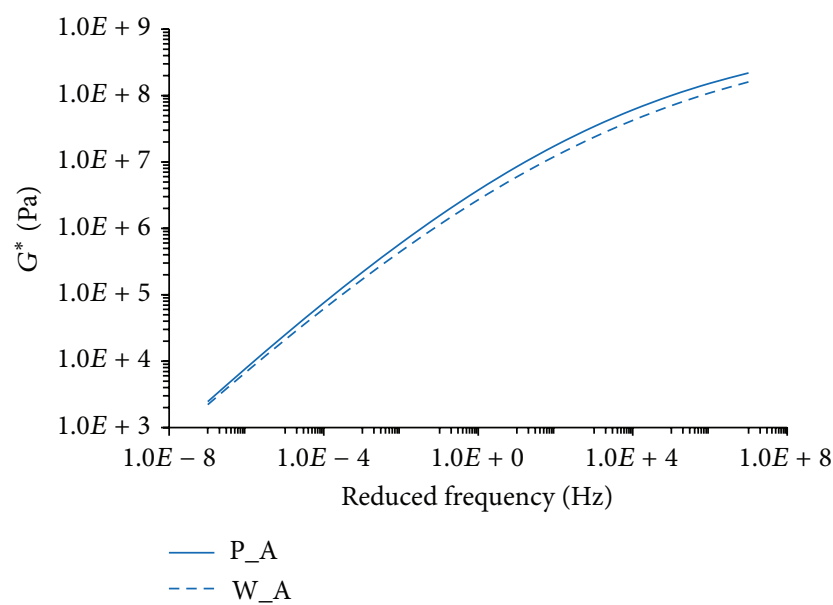

(a)

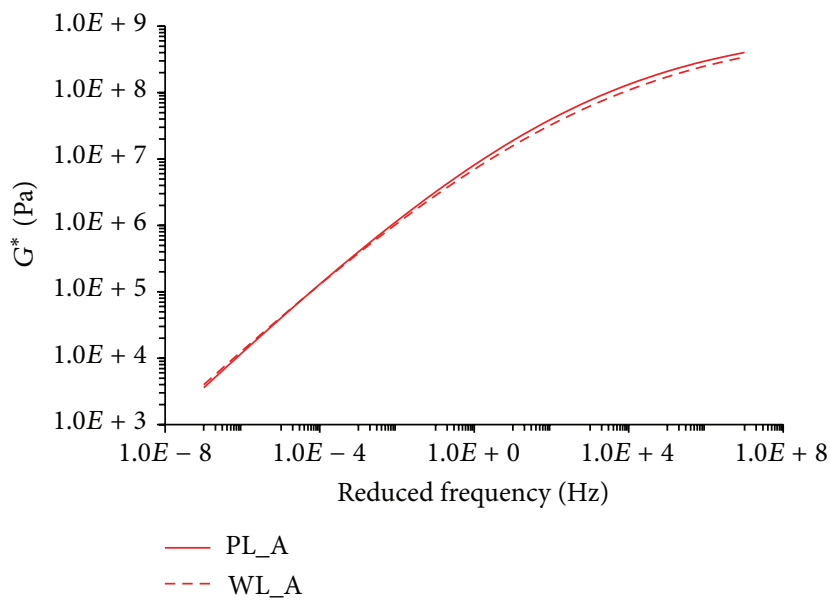

(c)

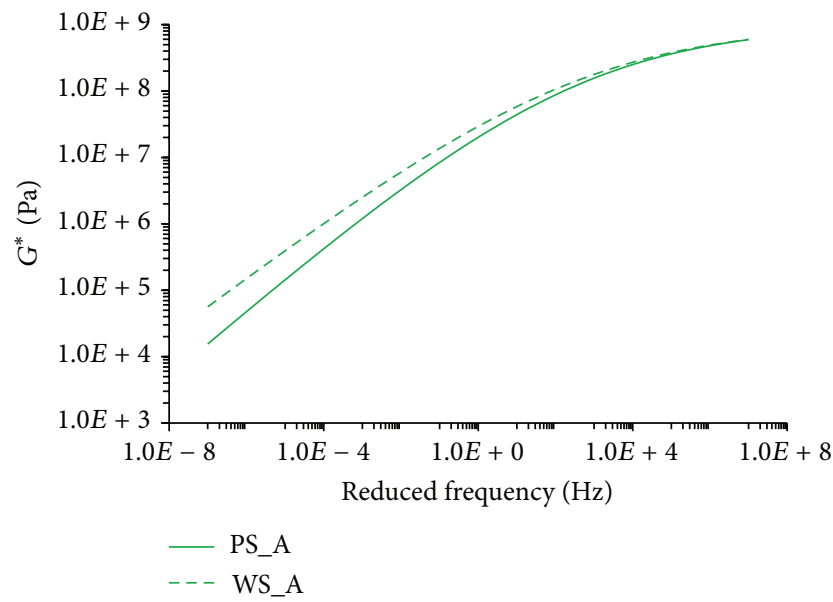

(e)

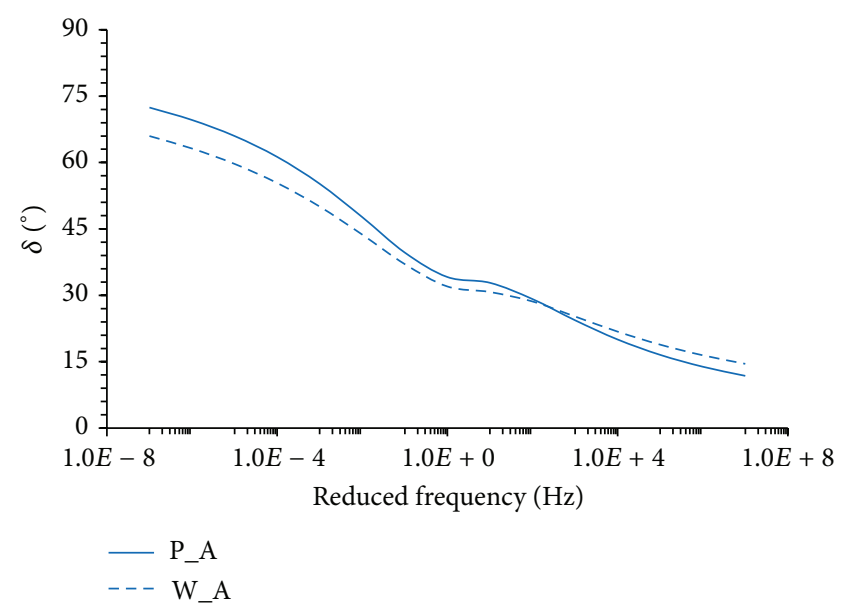

(b)

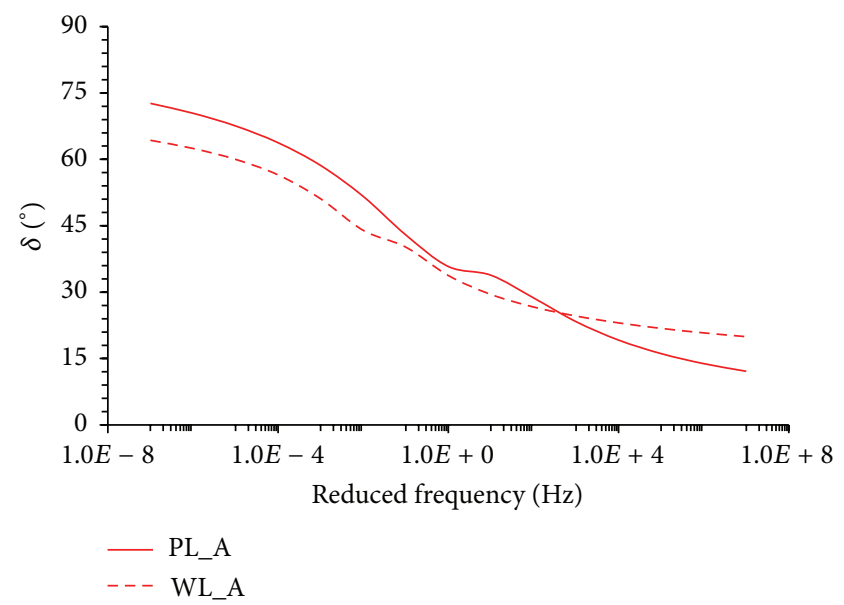

(d)

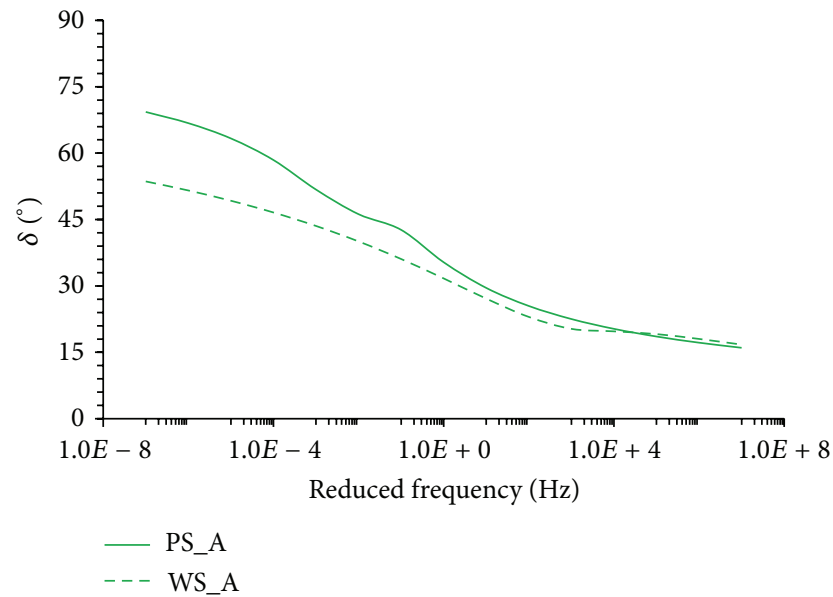

(f)

Figure 5: $G^{*}$ (left) and $\delta$ (right) master curves for binders (a, b), limestone mastics (c, d), and steel slag mastics (e, f). 


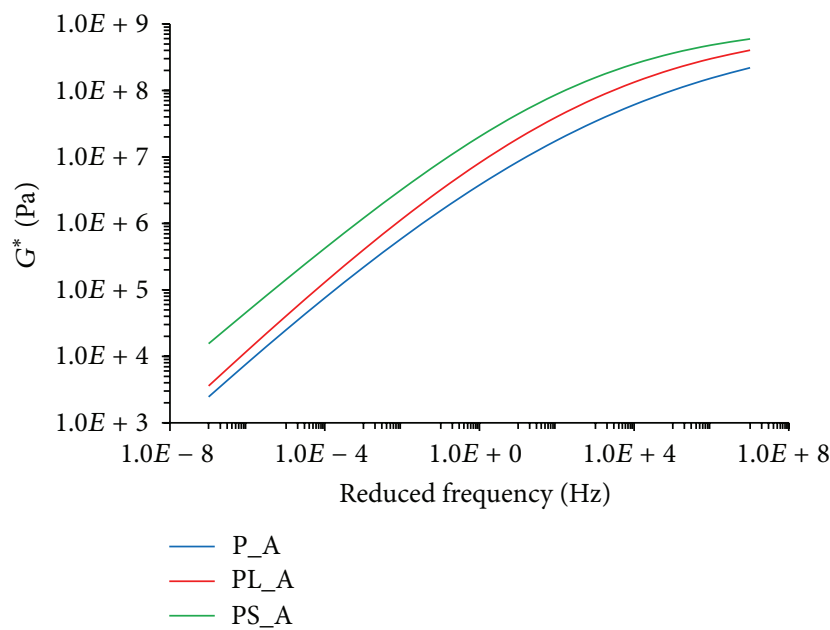

(a)

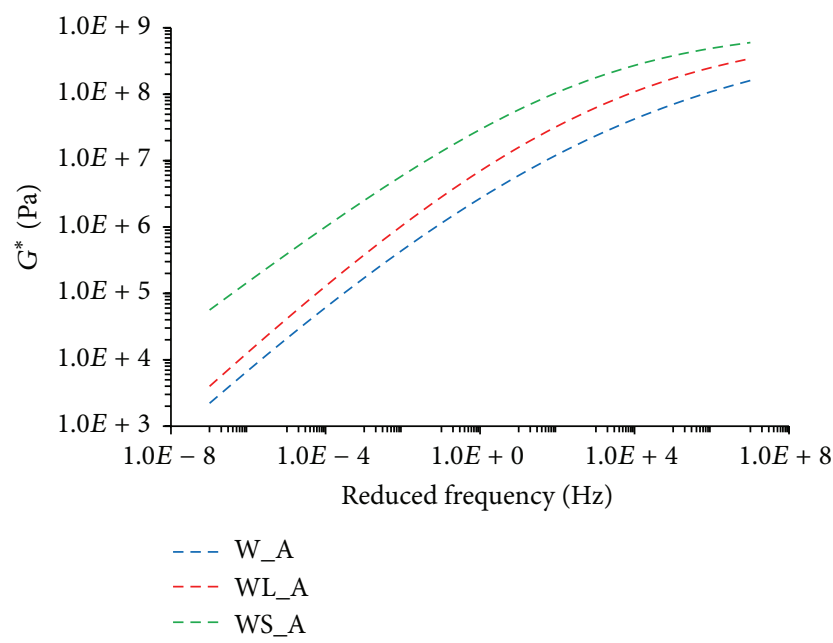

(c)

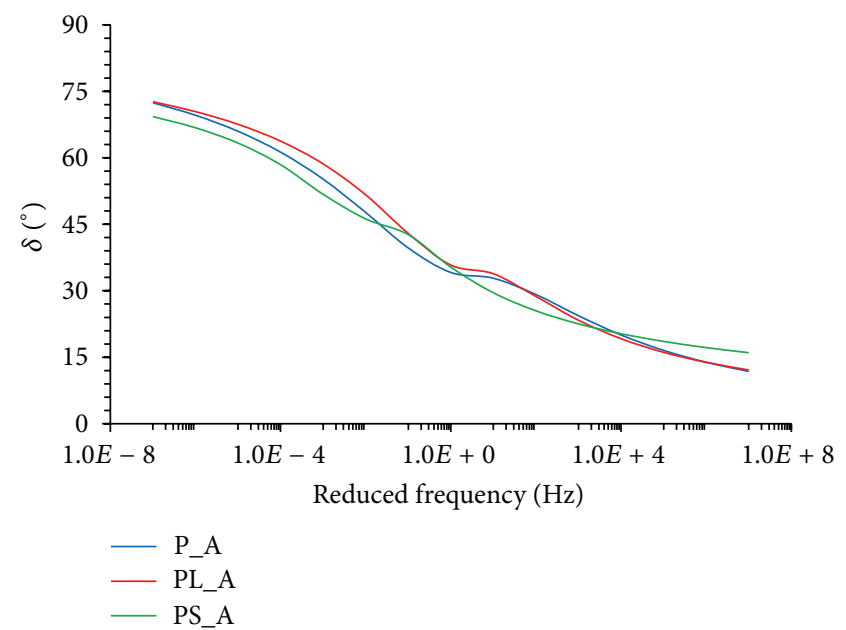

(b)

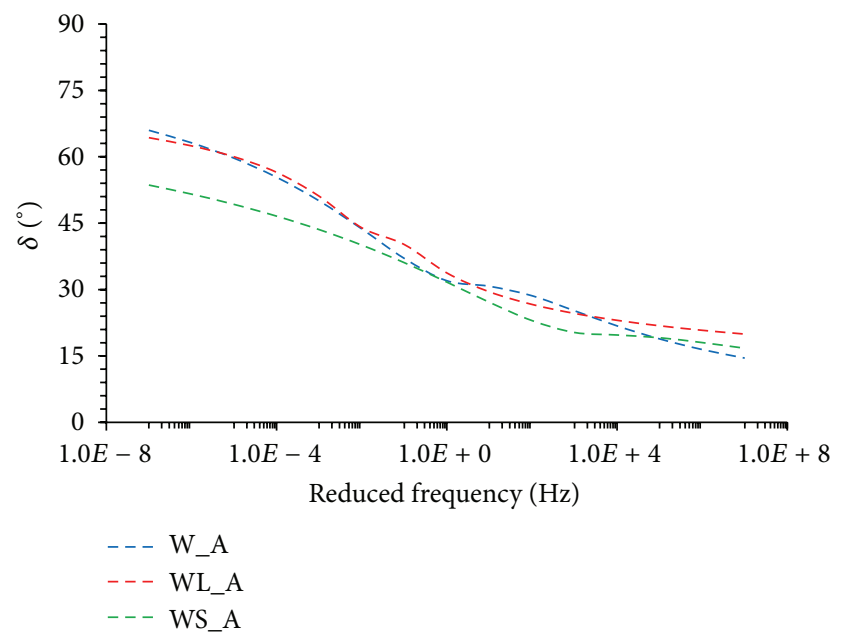

(d)

Figure 6: $G^{*}$ (left) and $\delta$ (right) master curves for hot (a, b) and warm (c, d) materials.

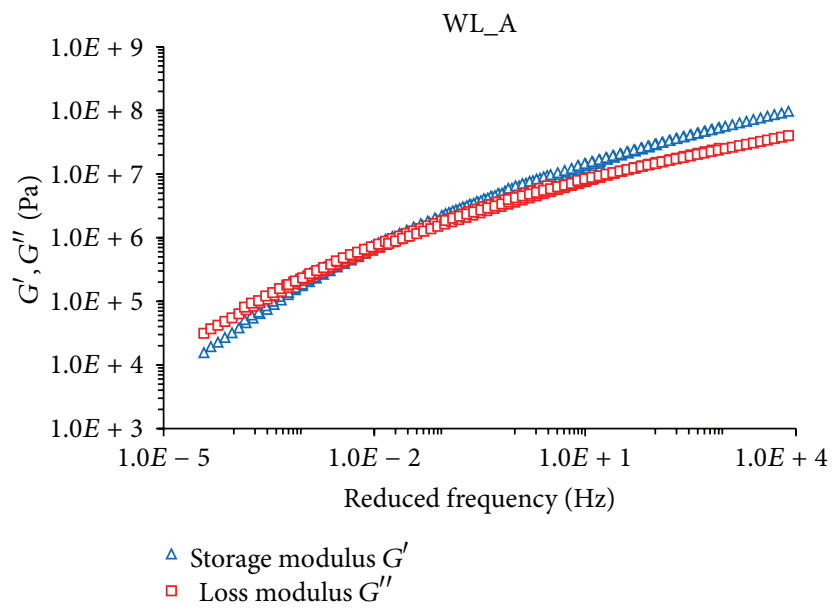

FIGURE 7: Storage and loss moduli versus frequency (sample WL_A). 


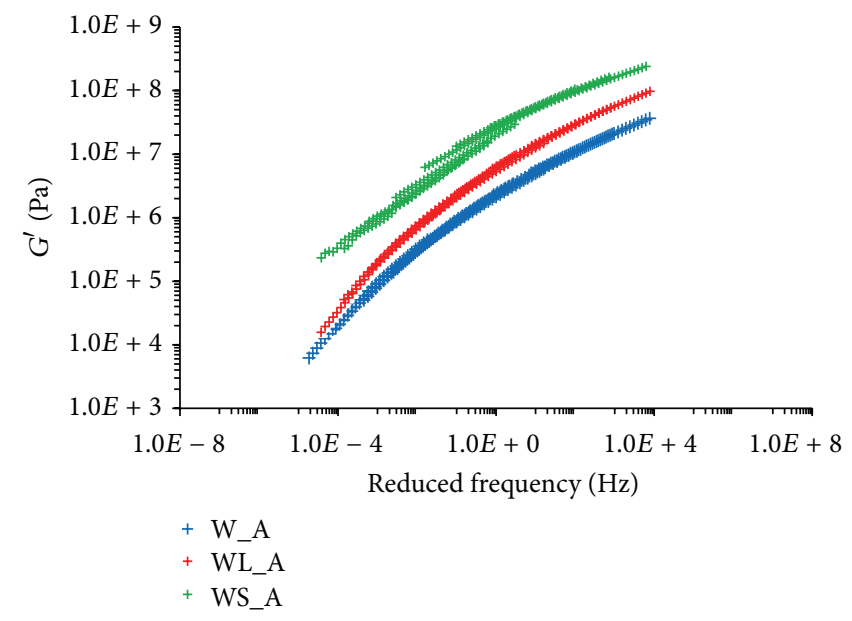

FIGURE 8: Storage modulus $G^{\prime}$ versus frequency (aged warm samples).

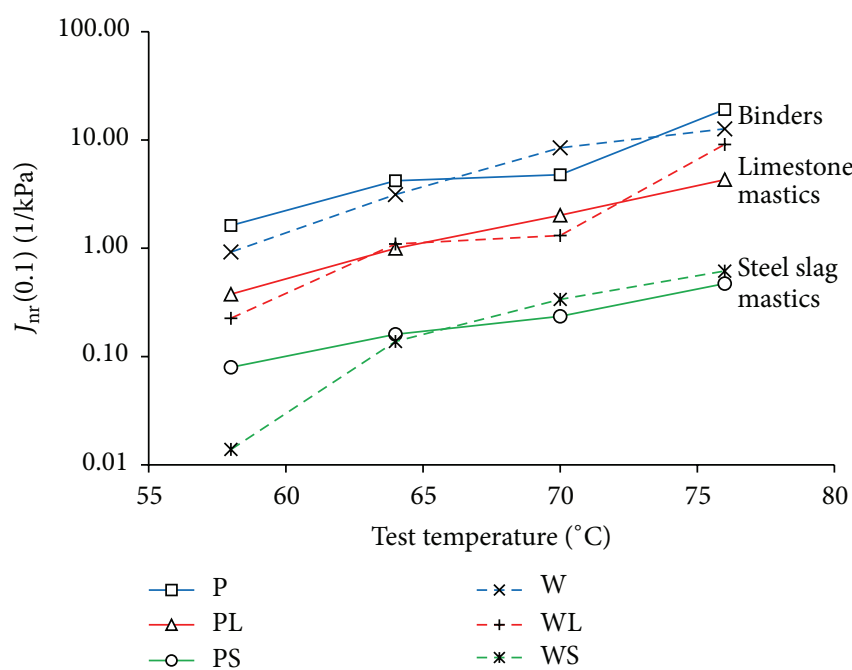

(a)

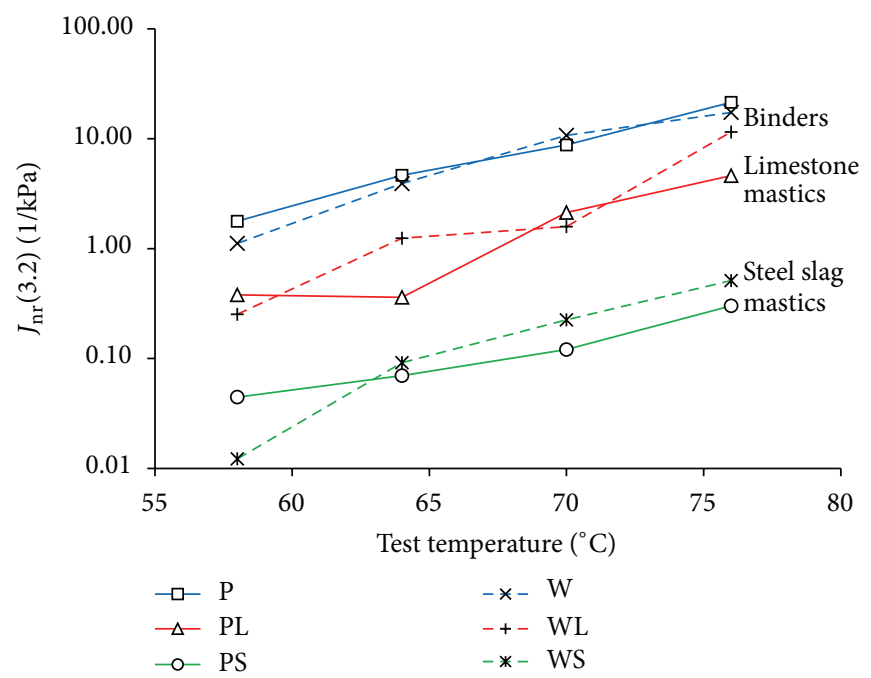

(b)

FIGURE 9: Nonrecoverable creep compliance $\left(J_{\mathrm{nr}}\right)$ of binders and mastics at $0.1(\mathrm{a})$ and $3.2(\mathrm{~b}) \mathrm{kPa}$.

prepared with chemical tensioactive additive. In particular, the rheological behaviour of warm bitumens and mastics at midrange and high service temperatures was evaluated through a dynamic shear rheometer.

Based on the obtained experimental results, the following main conclusions can be drawn:

(i) The time-temperature superposition principle seems generally valid for $G^{*}$ in the investigated range of reduced frequencies for both binders and mastics.

(ii) The most significant effect due to the warm modification is the reduced phase angle that suggests a more elastic response of the tested warm materials in the linear viscoelastic domain.

(iii) The addition of fillers leads to a stiffening effect, but a significant variation of the relaxation spectrum and rheological response in the linear viscoelastic domain towards a more elastic material is only detected in the case of EAF steel slag mastics.

(iv) The use of the warm chemical additive leads to equal or slightly reduced nonrecoverable creep compliance along with an enhanced resilient response demonstrating a general increase of the resistance to permanent deformation.

(v) Mastics generally show lower rutting potential with respect to the corresponding bitumens confirming the stiffening effect due to the addition of fillers.

(vi) Distinct antirutting performance is achieved for mastics containing EAF steel slag filler whereas noticeably lower improvements can be detected in the case of mastics prepared with limestone fillers, thereby confirming the physical-chemical interaction between fillers and bitumens. 


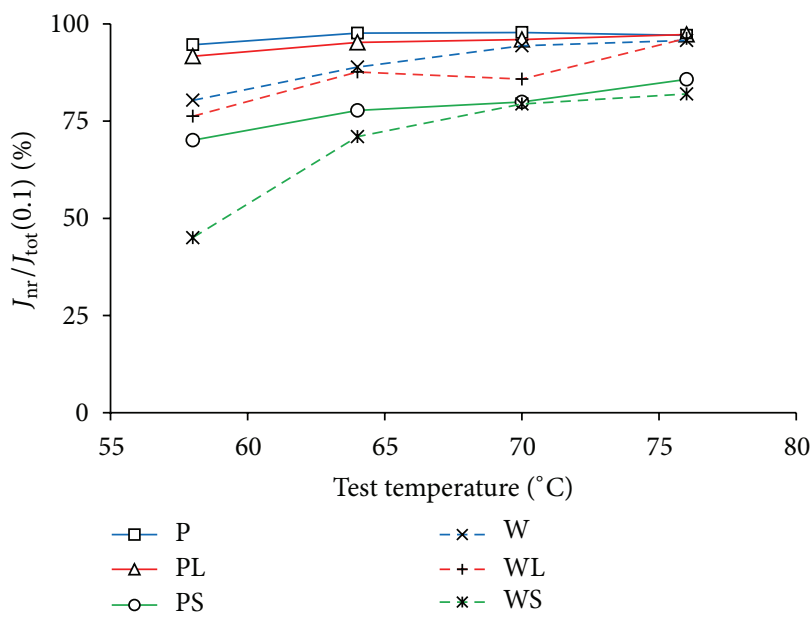

(a)

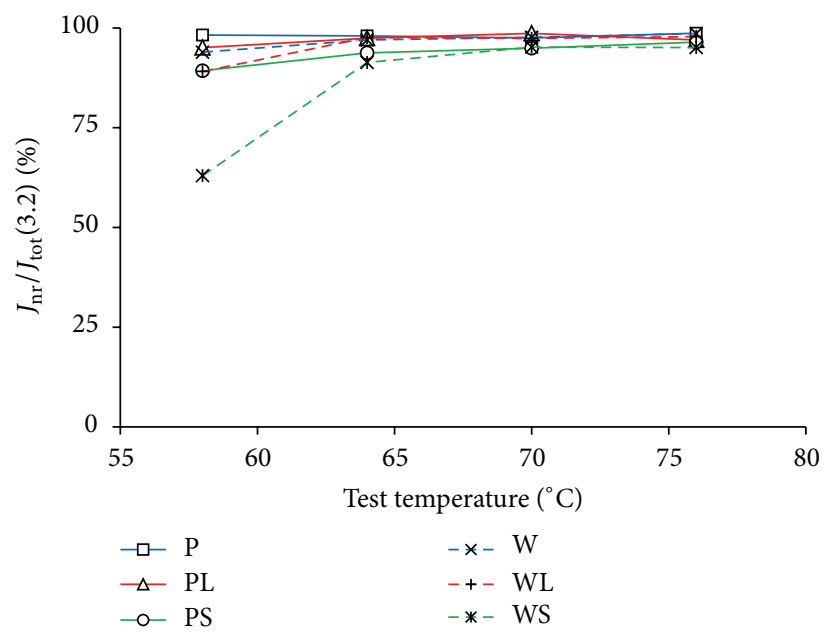

(b)

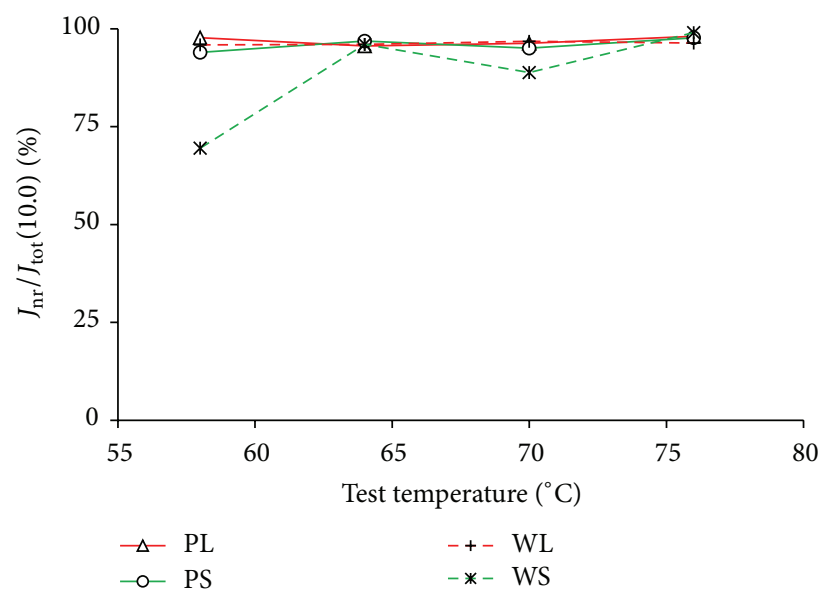

(c)

FIgURE 10: $J_{\text {nr }} / J_{\text {tot }}$ at stress level of 0.1 (a), 3.2 (b), and 10.0 (c) kPa.

Therefore, the results presented in this paper showed that warm materials prepared with chemical tensioactive additives and/or containing EAF steel slag filler seem to assure equal or even enhanced performance than the corresponding traditional hot materials, demonstrating promising applicability and confirming previous findings achieved within the same research project. In this sense, further research should be carried out to investigate mechanical properties and durability of such environmentally friendly asphalt mixtures in terms of moisture susceptibility and fatigue and low temperature cracking resistance. Moreover, field validation is also needed to fully promote the extensive use of such a material.

\section{Conflict of Interests}

The authors declare that there is no conflict of interests regarding the publication of this paper.

\section{References}

[1] M. C. Rubio, G. Martinez, L. Baena, and F. Moreno, "Warm mix asphalt: an overview," Journal of Cleaner Production, vol. 24, pp. 76-84, 2012.
[2] S. D. Capitão, L. G. Picado-Santos, and F. Martinho, "Pavement engineering materials: review on the use of warm-mix asphalt," Construction and Building Materials, vol. 36, pp. 1016-1024, 2012.

[3] E. Pasquini, G. Giacomello, M. Pasetto, and F. Canestrari, "Laboratory evaluation of the effect of low-temperature application of warm-mix asphalts on interface shear strength," Construction and Building Materials, vol. 88, pp. 56-63, 2015.

[4] F. Merusi and F. Giuliani, "Rheological characterization of wax-modified asphalt binders at high service temperatures," Materials and Structures, vol. 44, no. 10, pp. 1809-1820, 2011.

[5] F. Canestrari, A. Graziani, V. Pannunzio, and H. U. Bahia, "Rheological properties of bituminous binders with synthetic wax," International Journal of Pavement Research and Technology, vol. 6, no. 1, pp. 15-21, 2013.

[6] W. Zhao, F. Xiao, S. N. Amirkhanian, and B. J. Putman, "Characterization of rutting performance of warm additive modified asphalt mixtures," Construction and Building Materials, vol. 31, pp. 265-272, 2012.

[7] F. Xiao, V. S. Punith, and S. N. Amirkhanian, "Effects of nonfoaming WMA additives on asphalt binders at high performance temperatures," Fuel, vol. 94, pp. 144-155, 2012. 
[8] F. Morea, R. Marcozzi, and G. Castaño, "Rheological properties of asphalt binders with chemical tensoactive additives used in Warm Mix Asphalts (WMAs)," Construction and Building Materials, vol. 29, pp. 135-141, 2012.

[9] J. Zhang, G. Liu, L. Xu, and J. Pei, "Effects of WMA additive on the rheological properties of asphalt binder and high temperature performance grade," Advances in Materials Science and Engineering, vol. 2015, Article ID 467891, 7 pages, 2015.

[10] L. Mo, X. Li, X. Fang, M. Huurman, and S. Wu, "Laboratory investigation of compaction characteristics and performance of warm mix asphalt containing chemical additives," Construction and Building Materials, vol. 37, pp. 239-247, 2012.

[11] A. M. Rodríguez-Alloza, J. Gallego, I. Pérez, A. Bonati, and F. Giuliani, "High and low temperature properties of crumb rubber modified binders containing warm mix asphalt additives," Construction and Building Materials, vol. 53, pp. 460-466, 2014.

[12] N. M. Piatak, M. B. Parsons, and R. R. Seal II, "Characteristics and environmental aspects of slag: a review," Applied Geochemistry, vol. 57, pp. 236-266, 2015.

[13] I. Z. Yildirim and M. Prezzi, "Chemical, mineralogical, and morphological properties of steel slag," Advances in Civil Engineering, vol. 2011, Article ID 463638, 13 pages, 2011.

[14] T. Sofilić, V. Merle, A. Rastovčan-Mioč, M. Ćosić, and U. Sofilić, "Steel slag instead natural aggregate in asphalt mixture," Archives of Metallurgy and Materials, vol. 55, no. 3, pp. 657-668, 2010.

[15] S. Wu, Y. Xue, Q. Ye, and Y. Chen, "Utilization of steel slag as aggregates for stone mastic asphalt (SMA) mixtures," Building and Environment, vol. 42, no. 7, pp. 2580-2585, 2007.

[16] S. Sorlini, A. Sanzeni, and L. Rondi, "Reuse of steel slag in bituminous paving mixtures," Journal of Hazardous Materials, vol. 209-210, pp. 84-91, 2012.

[17] M. Pasetto and N. Baldo, "Mix design and performance analysis of asphalt concretes with electric arc furnace slag," Construction and Building Materials, vol. 25, no. 8, pp. 3458-3468, 2011.

[18] M. Pasetto and N. Baldo, "Performance comparative analysis of stone mastic asphalts with electric arc furnace steel slag: a laboratory evaluation," Materials and Structures, vol. 45, no. 3, pp. 411-424, 2012.

[19] P. Ahmedzade and B. Sengoz, "Evaluation of steel slag coarse aggregate in hot mix asphalt concrete," Journal of Hazardous Materials, vol. 165, no. 1-3, pp. 300-305, 2009.

[20] J. Xie, S. Wu, J. Lin, J. Cai, Z. Chen, and W. Wei, "Recycling of basic oxygen furnace slag in asphalt mixture: material characterization \& moisture damage investigation," Construction and Building Materials, vol. 36, pp. 467-474, 2012.

[21] J. Xie, J. Chen, S. Wu, J. Lin, and W. Wei, "Performance characteristics of asphalt mixture with basic oxygen furnace slag," Construction and Building Materials, vol. 38, pp. 796-803, 2013.

[22] Y. Xue, S. Wu, H. Hou, and J. Zha, "Experimental investigation of basic oxygen furnace slag used as aggregate in asphalt mixture," Journal of Hazardous Materials, vol. 138, no. 2, pp. 261268, 2006.

[23] F. Autelitano and F. Giuliani, "Swelling behavior of electric arc furnace aggregates for unbound granular mixtures in road construction," International Journal of Pavement Research and Technology, vol. 8, no. 2, pp. 103-111, 2015.

[24] M. Ameri, S. Hesami, and H. Goli, "Laboratory evaluation of warm mix asphalt mixtures containing electric arc furnace (EAF) steel slag," Construction and Building Materials, vol. 49, pp. 611-617, 2013.
[25] H. Wang, I. L. Al-Qadi, A. F. Faheem, H. U. Bahia, S.-H. Yang, and G. H. Reinke, "Effect of mineral filler characteristics on asphalt mastic and mixture rutting potential," Transportation Research Record, vol. 2208, pp. 33-39, 2011.

[26] A. F. Faheem and H. U. Bahia, "Modelling of asphalt mastic in terms of filler-bitumen interaction," Road Materials and Pavement Design, vol. 11, no. 1, pp. 281-303, 2010.

[27] Y. R. Kim and D. N. Little, "Linear viscoelastic analyis of asphalt mastics," ASCE Journal of Materials in Civil Engineering, vol. 16, no. 2, pp. 122-132, 2004.

[28] F. Cardone, F. Frigio, G. Ferrotti, and F. Canestrari, "Influence of mineral fillers on the rheological response of polymer-modified bitumens and mastics," Journal of Traffic and Transportation Engineering, vol. 2, no. 6, pp. 373-381, 2015.

[29] J.-S. Chen, P.-H. Kuo, P.-S. Lin, C.-C. Huang, and K.-Y. Lin, "Experimental and theoretical characterization of the engineering behavior of bitumen mixed with mineral filler," Materials and Structures, vol. 41, no. 6, pp. 1015-1024, 2008.

[30] W. Grabowski and J. Wilanowicz, "The structure of mineral fillers and their stiffening properties in filler-bitumen mastics," Materials and Structures, vol. 41, no. 4, pp. 793-804, 2008.

[31] B. S. Underwood and Y. R. Kim, "Nonlinear viscoelastic analysis of asphalt cement and asphalt mastics," International Journal of Pavement Engineering, vol. 16, no. 6, pp. 510-529, 2015.

[32] F. Frigio, G. Ferrotti, and F. Cardone, "Fatigue rheological characterization of polymer-modified bitumens and mastics," in Proceedings of the 8th International RILEM SIB Symposium, Ancona, Italy, October 2015.

[33] M. Pasetto, G. Giacomello, E. Pasquini, and F. Canestrari, "Effect of warm mix chemical additives on the binder-aggregate bond strength and high-service temperature performance of asphalt mixes containing electric arc furnace steel slag," in Proceedings of the 8th International RILEM SIB Symposium, Ancona, Italy, October 2015.

[34] T. W. Kennedy, G. A. Huber, E. T. Harrigan et al., Superior Performing Asphalt Pavement (Superpave): The Product of the SHRP Asphalt Research Program, Strategic Highway Research Program, National Research Council, Washington, DC, USA, 1994.

[35] M. L. Williams, R. F. Landel, and J. D. Ferry, "The temperature dependence of relaxation mechanisms in amorphous polymers and other glass-forming liquids," Journal of the American Chemical Society, vol. 77, no. 14, pp. 3701-3707, 1955.

[36] H. U. Bahia, D. I. Hanson, M. Zeng et al., "Characterization of modified asphalt binders in superpave mix design," NCHRP Report 459, National Cooperative Highway Research Program, Washington, DC, USA, 2011.

[37] NCHRP, "Test methods and specification criteria for mineral filler used in HMA," NCHRP Report 9-45, National Cooperative Highway Research Program, Washington, DC, USA, 2011.

[38] S. W. Ko, R. K. Gupta, S. N. Bhattacharya, and H. J. Choi, "Rheology and physical characteristics of synthetic biodegradable aliphatic polymer blends dispersed with MWNTs," Macromolecular Materials and Engineering, vol. 295, no. 4, pp. 320-328, 2010.

[39] E. Santagata, O. Baglieri, D. Dalmazzo, and L. Tsantilis, "Evaluation of the anti-rutting potential of polymer-modified binders by means of creep-recovery shear tests," Materials and Structures, vol. 46, no. 10, pp. 1673-1682, 2013. 

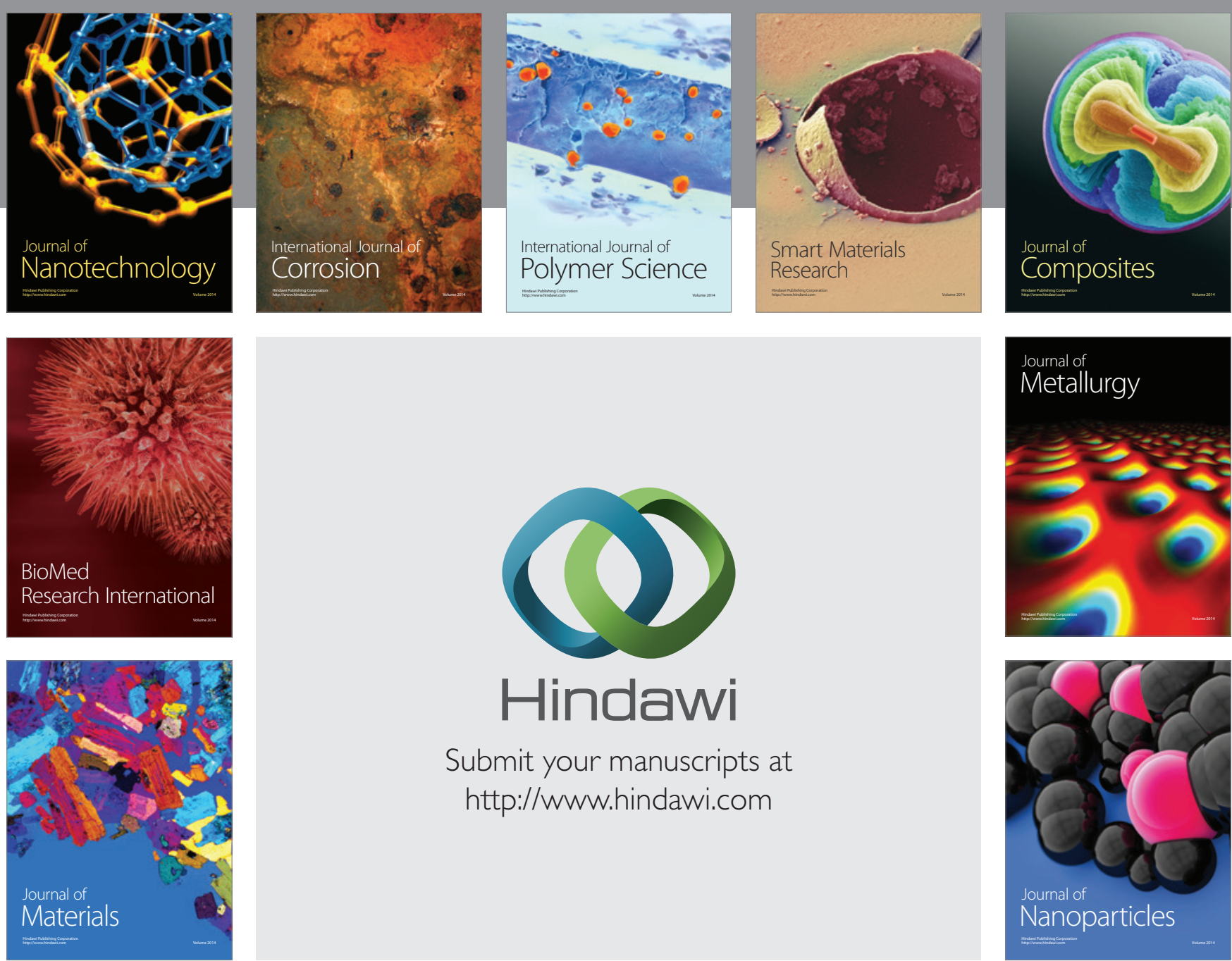

\section{Hindawi}

Submit your manuscripts at

http://www.hindawi.com

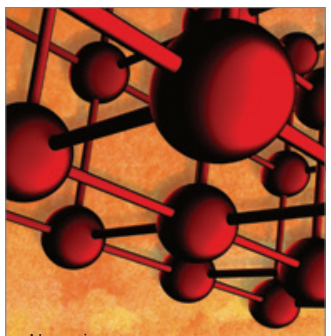

Materials Science and Engineering
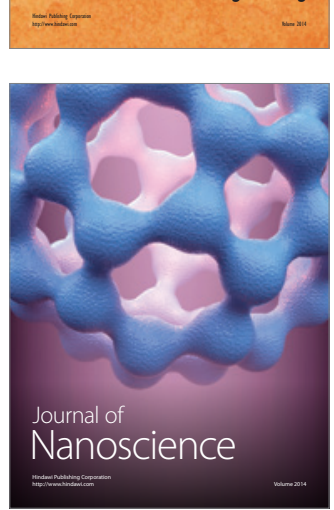
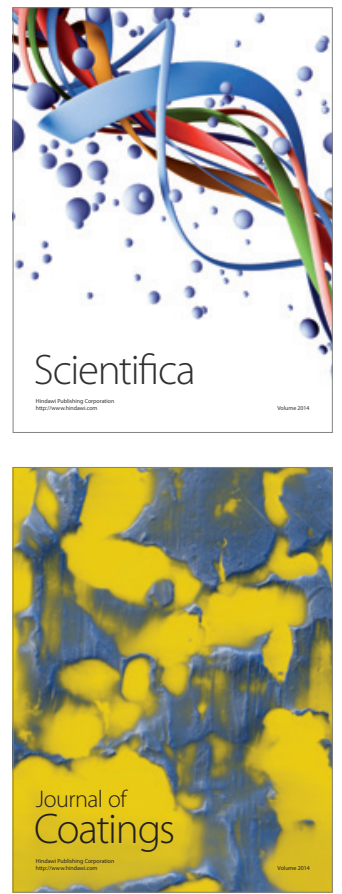
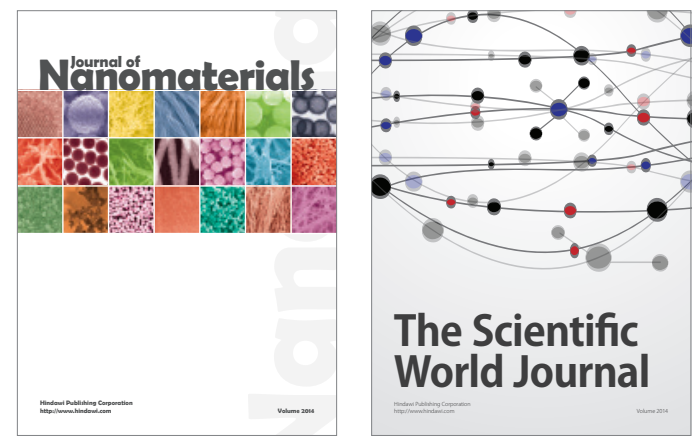

The Scientific World Journal
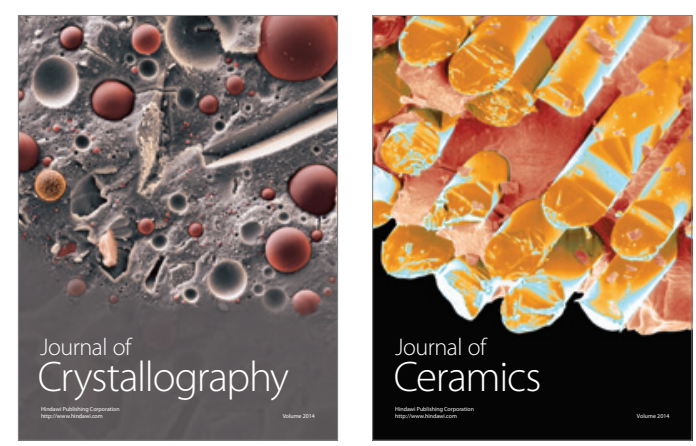
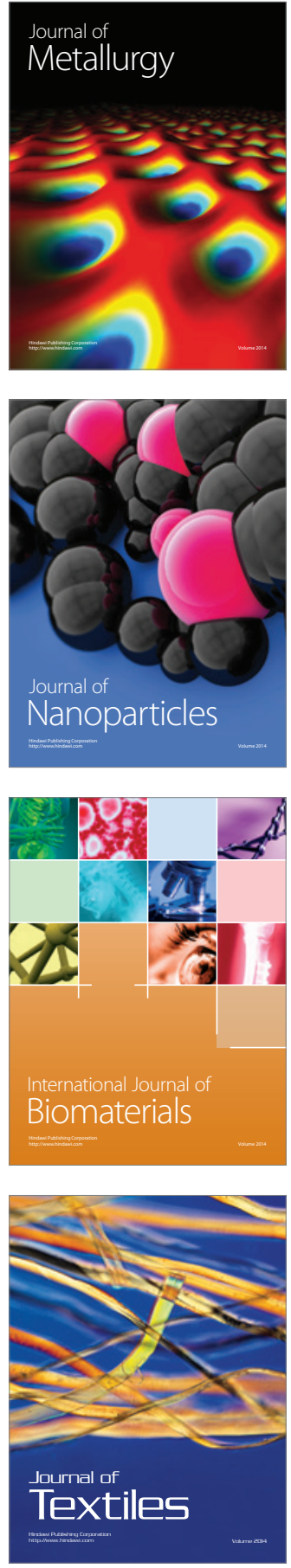